\title{
MALBA TAHAN + MATEMÁTICA = MALBATEMÁTICA
}

\author{
MALBA TAHAN + MATH = \\ MALBATEMÁTICA
}

\section{MALBA TAHAN + MATEMÁTICA = MALBATEMÁTICA}

\section{RESUMO}

Malbatemática foi o nome dado à exposição em homenagem ao professor Julio Cesar de Mello e Souza, mais conhecido pelo seu pseudônimo, Malba Tahan. A exposição, organizada pelo Grupo de Estudos e Pesquisa em Educação Matemática nos/dos Anos Iniciais - GEPEMAI -, trouxe à mostra objetos, fotos, cartas, manuscritos e publicações daquele que é considerado um precursor da Educação Matemática brasileira, para a qual sua contribuição foi e ainda é imensa, justificando a escolha da data 6 de maio, dia de seu nascimento, como o Dia Nacional da Matemática. O objetivo deste texto é divulgar a vida, a obra, o legado e a contribuição de Malba Tahan para a educação matemática. O acervo completo de Malba Tahan encontra-se sob custódia do Centro de Memória da Faculdade de Educação da Universidade Estadual de Campinas - FE/UNICAMP.

PALAVRAS-CHAVE: Malba Tahan. Educação Matemática. Memória. Documentos.

\section{ABSTRACT}

Malbatemática was the name given to the exhibition in honor of Professor Julio Cesar de Mello e Souza, better known by his pseudonym, Malba Tahan. The exhibition, organized by the Group of Studies and Research in Mathematics Education in / of the Elementary Years - GEPEMAI - showed objects, photos, letters, manuscripts and publications of the one who is considered a precursor of brazilian Mathematics Education, to which his contribution was and still is immense, justifying the choice of May 6, the day of his birth, as the Mathematics National Day. The aim of this paper is to promote the life, the work, the legacy and the contribution of Malba Tahan to mathematics education. The complete collection of Malba Tahan is in custody of the Center for Memory of the Faculty of Education of the State University of Campinas - FE / UNICAMP.

KEYWORDS: Malba Tahan. Mathematics Education. Memory. Documents

\section{RESUMEN}

Malbatemática fue el nombre dado a la exposición en honor al profesor Julio Cesar de Mello e Souza, más conocido por el seudónimo Malba Tahan. La exposición, organizada por el Grupo de Estudios e Investigación

\footnotetext{
${ }^{1}$ Mestre em Educação pela FE/Unicamp. Professora dos Anos Iniciais do Ensino Fundamental da Prefeitura Municipal de Paulínia. Membro do Grupo de Estudos e Pesquisa em Educação Matemática nos/dos Anos Iniciais (GEPEMAI) da FE/Unicamp. E-mail: rosanabiani@gmail.com

${ }^{2}$ Pós-doutorado em Educação Matemática pela Université Laval/Canadá. Professor colaborador da Faculdade de Educação/Unicamp. Coordenador do Grupo de Estudos e Pesquisa em Educação Matemática nos/dos Anos Iniciais(GEPEMAI) da FE/Unicamp. Doutorado em Ciências Humanas - Universidade Estadual de Campinas (UNICAMP) - Campinas, São Paulo - Brasil. Professor Colaborador - Universidade Estadual de Campinas (UNICAMP) - Campinas, São Paulo - Brasil. E-mail: slorenzato@sigmanet.com.br
}

Submetido em: 25/09/2016 - Aceito em: 09/01/2017

(C) ETD-Educação Temática Digital Campinas, SP $\quad$ v.19 n.3 $\quad$ p. 822-843 jul./set. 2017


en Educación para la enseñanza de las Matemáticas de los primeros años - GEPEMAI - presenta objetos, fotografías, cartas, manuscritos y publicaciones lo que permite considerarlo el precursor en el ámbito de la Educación en Brasil, para la enseñanza de las matemáticas. Su contribución ha sido y sigue siendo inmensa, razón por la cual se eligió el día 6 de mayo, fecha de su nacimiento, como el Día Nacional de las Matemáticas en Brasil. El objetivo de este texto es hacer conocer la vida, obra y legado de Malba Tahan en la enseñanza de las matemáticas. La colección completa de Malba Tahan está bajo la responsabilidad del Centro de Memoria de la Facultad de Educación de la Universidad Estatal de Campinas-FE/UNICAMP.

PALABRAS-CLAVE: Malba Tahan. Enseñanza de las Matemáticas. Memoria. Documentos.

\section{INTRODUÇÃO}

Em 26 de junho de 2013, depois de muito tramitar pelo Congresso Nacional, foi transformado em Lei Ordinária o projeto que institui o dia 6 de maio, o Dia Nacional da Matemática. Esse dia foi escolhido em homenagem a Julio Cesar de Mello e Souza', mais conhecido pelo seu pseudônimo, Malba Tahan, que nasceu em 6 de maio de 1895, na cidade do Rio de Janeiro. A Lei 12 835/2013 (BRASIL, 2013) foi publicada no Diário Oficial da União (D.O.U) em 27 de junho de 2013 (Figura 1).

\section{Presidência da República \\ Casa Civil \\ Subche fia para Assuntos Juridicos}

LEI N 12.835, DE 26 DE JUNHO DE 2013.

Institui o Dia Nacional da Matemática.

A PRESIDENTA DA REPÚBLICA Faço saber que o Congresso Nacional decreta e eu sanciono a seguinte Lei:

Art. $1^{\circ}$ Fica instituido o Dia Nacional da Matemática, a ser comemorado anualmente em todo o território nacional no dia 6 de maio, data de nascimento do matemático, educador e escritor MALBA TAHAN.

Art. $2^{\circ} \mathrm{O}$ Poder Executivo incentivará a promoção de atividades educativas e culturais alusivas à referida data.

Art. $3^{\circ}$ Esta Lei entra em vigor na data de sua publicação.

Brasilia, 26 de junho de $2013 ; 192^{\circ}$ da Independência e $125^{\circ}$ da República.

DILMA ROUSSEFF

Aloizio Mercadante

FIGURA 1 - Publicação da Lei 12 835/2013

Fonte: [Diário Oficial da União (D.O.U), 27/06/2013, p. 01, col. 03. Disponível em: http://www.jusbrasil.com.br/diarios/56016228/dou-secao-1-27-06-2013-pg-1]

Existem muitos motivos para justificar essa homenagem. Julio Cesar de Mello e Souza faz parte da História da Educação Matemática brasileira. Engenheiro, pesquisador, escritor, editor, didata, autor, conferencista, professor, em seus 60 anos de atividade 
literária publicou cerca de 123 livros. Desses, 75 são referentes à Matemática e 48 são romances. Sua obra é vasta, de conteúdo bastante diversificado, e inclui romances, livros didáticos, contos, novelas, lendas, artigos, dentre outros.

Dentre suas obras mais famosas estão $O$ homem que calculava e Didática $d a$ Matemática. Sobre o autor, Siqueira Filho (2008, p. 37) afirma: “... a existência de 'dois autores', isto é: um, que escrevia histórias fantasiosas recorrendo a temáticas orientais; outro, que discorria sobre assuntos específicos do conhecimento matemático". Os "dois autores" foram brilhantes.

Nas décadas em que viveu e trabalhou Julio Cesar de Mello e Souza, o ensino e a aprendizagem da Matemática tinham marcadamente características da pedagogia tradicional: o processo de ensino-aprendizagem se dava por transmissão, memorização e repetição dos conteúdos; a metodologia baseava-se na preparação e na apresentação dos conteúdos pelo professor, que os transmitia aos alunos, e depois o aluno respondia nas lições se havia assimilado o conteúdo ensinado. Isso era válido para qualquer idade ou série. Era basicamente essa a realidade do ensino de Matemática que Julio Cesar via acontecer e com a qual não concordava.

As aulas eram expositivas; havia muitos ditados e cópias; a Geometria era um amontoado de demonstrações ou de inúteis medições; a Álgebra era confundida com o algebrismo, que Julio Cesar chamava de "o entulho da Matemática"; a Aritmética se resumia a definições, fórmulas, propriedades e exercícios. Não se falava em aprendizagem, nem em Educação Matemática: só em Matemática. Os programas das disciplinas e a metodologia de ensino eram arcaicos e inflexíveis; não havia qualquer possibilidade para críticas e, menos ainda, para mudanças.

A Matemática era a disciplina que mais reprovava os alunos e, por isso, considerada a mais difícil e a mais temida dos estudantes. O próprio Julio Cesar não era um aluno brilhante em Matemática, quer dizer, não tirava boas notas: 6, 7, 8-o que é bem diferente. Em desenho era ainda pior: $6,3,1$. Provavelmente porque a maneira como essas disciplinas eram ensinadas era aquela que mais tarde Julio condenaria, por mais dificultarem do que facilitarem a aprendizagem dos alunos.

Por essa época, ao que parecia, Julio Cesar não tinha "vocação" para a Matemática, mas o futuro provaria o contrário, e ele se tornaria professor, justamente, de Matemática. E, como sabemos, um professor brilhante.

Foi nesse cenário que surgiu Malba Tahan, como inovador, divulgador, protagonista de alternativas didático-pedagógicas para uma Matemática escolar até então pouco ou nada 
praticada. E despontou, ao mesmo tempo, como herege e como arauto. Herege, pois se posicionava contra dogmas matemáticos de sua época, como a memorização do conteúdo pelo conteúdo e o alto índice de reprovação dos alunos como mérito do professor. Era contra o matemático que desejasse "... complicar, dificultar, e tornar obscuro o ensino da Matemática" (TAHAN, 1965, p. 61). Arauto, pois anunciava mudanças necessárias - e as praticava.

Em Didática da Matemática (1961/1962) é possível perceber o herege e o arauto: ali Malba Tahan se posiciona claramente sobre o ensino e a aprendizagem da Matemática. No volume I, o herege faz fortes críticas ao ensino da época e, no volume II, o arauto apresenta propostas e faz recomendações aos professores para o ensino de uma matemática mais humanizada.

O que Julio Cesar criticava era fazer, na escola, uma Matemática que seria só para matemáticos ou uma "matemática algebrista", das teorias intrincadas, dos problemas complicados e fora da vida real, dos cálculos trabalhosos dos quais os estudantes nada aproveitam, das demonstrações longas e enfadonhas (TAHAN,1965).

O que Malba Tahan anunciava era uma Matemática diferente. Era arauto de outra concepção de Matemática e de ensino e aprendizagem de Matemática. O que ele propunha era uma Matemática para todos ou uma "educação matemática". Lorenzato (2010, p. 51) nos esclarece a diferença:

\footnotetext{
Para aqueles que são ou pretendem ser matemáticos, essa ciência pode ser concebida como um fim em si mesmo, porque o ato de fazer ou criar matemática Ihes proporciona deleite e isso acontece por opção de vida. No entanto, os professores de matemática do ensino fundamental ou médio têm como objetivo maior em seu exercício profissional proporcionar aos alunos a aprendizagem da matemática elementar, para que estes possam melhorar suas condições de vida através da utilização de conhecimentos matemáticos. Assim sendo, a matemática deve ser interpretada pelos professores como instrumento para a vida e não um fim em si mesmo.
}

Nesse sentido, as propostas e as recomendações de Malba Tahan iam ao encontro da educação matemática que ele defendia ser para todos: propiciar que o aluno redescubra a Matemática; conceber o erro como algo positivo e normal no processo de aprendizagem; refletir sobre para quem, o quê, para quê e como ensinar Matemática; jogar para aprender ou aprender jogando; montar o Laboratório de Ensino de Matemática (LEM) com materiais didáticos e bibliografia a respeito da construção e do uso do LEM; usar o método heurístico de ensino; utilizar paradoxos, falácias, lendas, desafios, recreações nas aulas de Matemática; apresentar problemas interessantes aos alunos; contar histórias; utilizar a História da Matemática como apoio didático; integrar língua materna com linguagem 
matemática e integrar Matemática com outras disciplinas.

Mas, mais do que elencar propostas, o que merece ser destacado em sua obra é o valor da sua contribuição para a educação matemática. Contribuição que, podemos afirmar, justifica o merecimento da homenagem que recebe e lhe confere a notoriedade devida na comunidade matemática brasileira. Contribuição que reside, principalmente, no fato de que, por meio do seu trabalho e de sua obra, com vistas ao ensino da Matemática, Malba Tahan obteve um protagonismo que o alçou ao hall dos precursores e o tornou um marco na história da Educação Matemática brasileira. Para Oliveira (2001, p. 16),

reconhecer e analisar o educador Julio Cesar de Mello e Sousa é permitir que suas ideias invadam nossas atuais tendências de ensino de matemática. Mergulhar nos contos orientais de Malba Tahan é deixar que a fantasia, a cultura e os ensinamentos filosóficos e espiritualistas, ultrapassem os padrões acadêmicos formais e estabeleçam uma conexão direta com nossas próprias inquietações na educação.

Essas foram razões que motivaram o Grupo de Estudos e Pesquisa em Educação Matemática nos/dos Anos Iniciais (GEPEMAI)i a organizar a Exposição "Malbatemática: Homenagem à vida e à obra de Malba Tahan" (Figura 2).

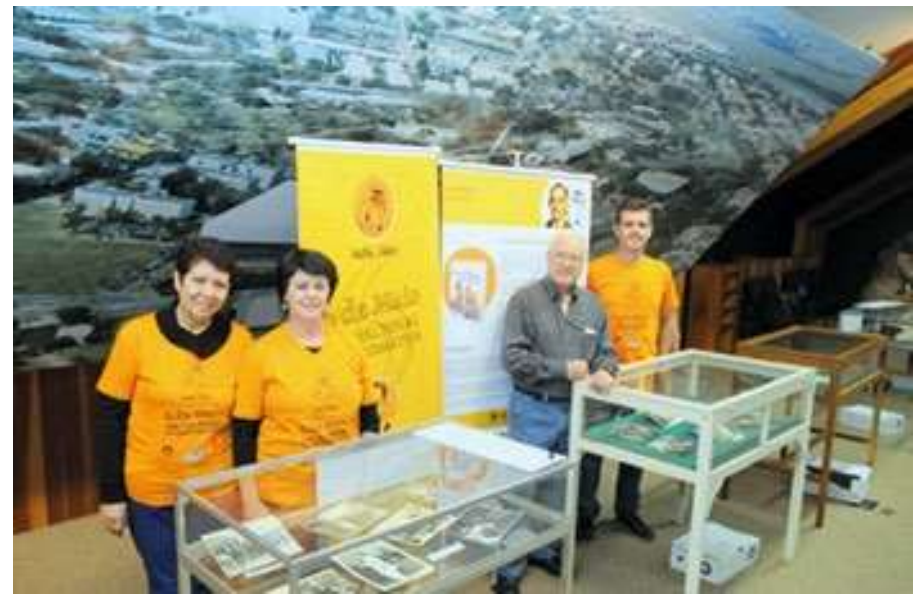

FIGURA 2 - Sergio Lorenzato e membros do GEPEMAI na abertura da Exposição Malbatemática Fonte: [SUGIMOTO, 2015 “O ensinar e o aprender matemática e o tributo ao homem que calculava”, Jornal da Unicamp, 06/jul/2015. Disponível em: http://www.unicamp.br/unicamp/noticias/2015/07/06/o-ensinar-eaprender-matematica-e-o-tributo-ao-homem-que-calculava]

O grupo também compartilha das ideias de Malba Tahan, na medida em que concorda que a Matemática é para todos; que ela não pode e não deve ser considerada árida e triste, inútil e enfadonha (TAHAN, 1961); e que a ação educativa do professor precisa buscar não apenas tornar a matemática interessante, compreensível e admirável aos olhos 
dos alunos, mas também melhorar o ensino e a aprendizagem dessa disciplina que continua sendo vista como difícil e ainda é uma das que mais reprova os alunos.

Sergio Lorenzato, professor colaborador da Faculdade de Educação (FE) da Universidade Estadual de Campinas (UNICAMP) e coordenador do GEPEMAI, foi aluno de Malba Tahan em 1958, no curso "Metodologia da Matemática na Escola Primária", realizado por iniciativa da Campanha de Aperfeiçoamento e Difusão do Ensino Secundário (CADES) e do Ministério da Cultura (MEC). Lorenzato afirma que foi após esse curso que decidiu ser professor de Matemática, porque "... o mestre tornava suas aulas muito agradáveis e, aos que as assistiam, a Matemática se apresentava compreensível e fortemente admirável" (LORENZATO, 1995, p. 95); e dessa matemática ele queria ser professor.

O professor Malba Tahan escolheu, especificamente, para esse curso

o "método eclético com caderno controlado" e explicava: "chama-se 'eclético' porque lança mão de tudo de bom que os outros métodos possuem e 'caderno controlado', porque cada aluno fará seu caderno, que será avaliado ao final do curso". Esse caderno deveria conter o registro das aulas, sendo um assunto em cada página (páginas numeradas), em diferentes cores e com ilustrações; todas as aferições de rendimento escolar também deveriam estar anexadas ao caderno e este se encerrava com uma auto-crítica (do autor do caderno). Finalmente, todos os cadernos da turma seriam avaliados pelo professor e todos eles participariam de uma exposição, no final do ano, aberta ao público. E isto assim foi feito, tendo cada professor organizado o seu caderno, o qual começava pelo "algebrismo", a que o mestre chamava de "entulho da matemática" (LORENZATO, 1995, p. 95-96, grifos do autor).

Lorenzato ainda guarda o exemplar do livro $O$ homem que calculava (Figura 3), no qual consta a dedicatória de Malba Tahan, bem como o caderno de curso que exibe, na página 49, o carimbo do professor com seu nome árabe. Malba Tahan olhava os cadernos todos os dias e carimbava alguma página (Figura 4). 


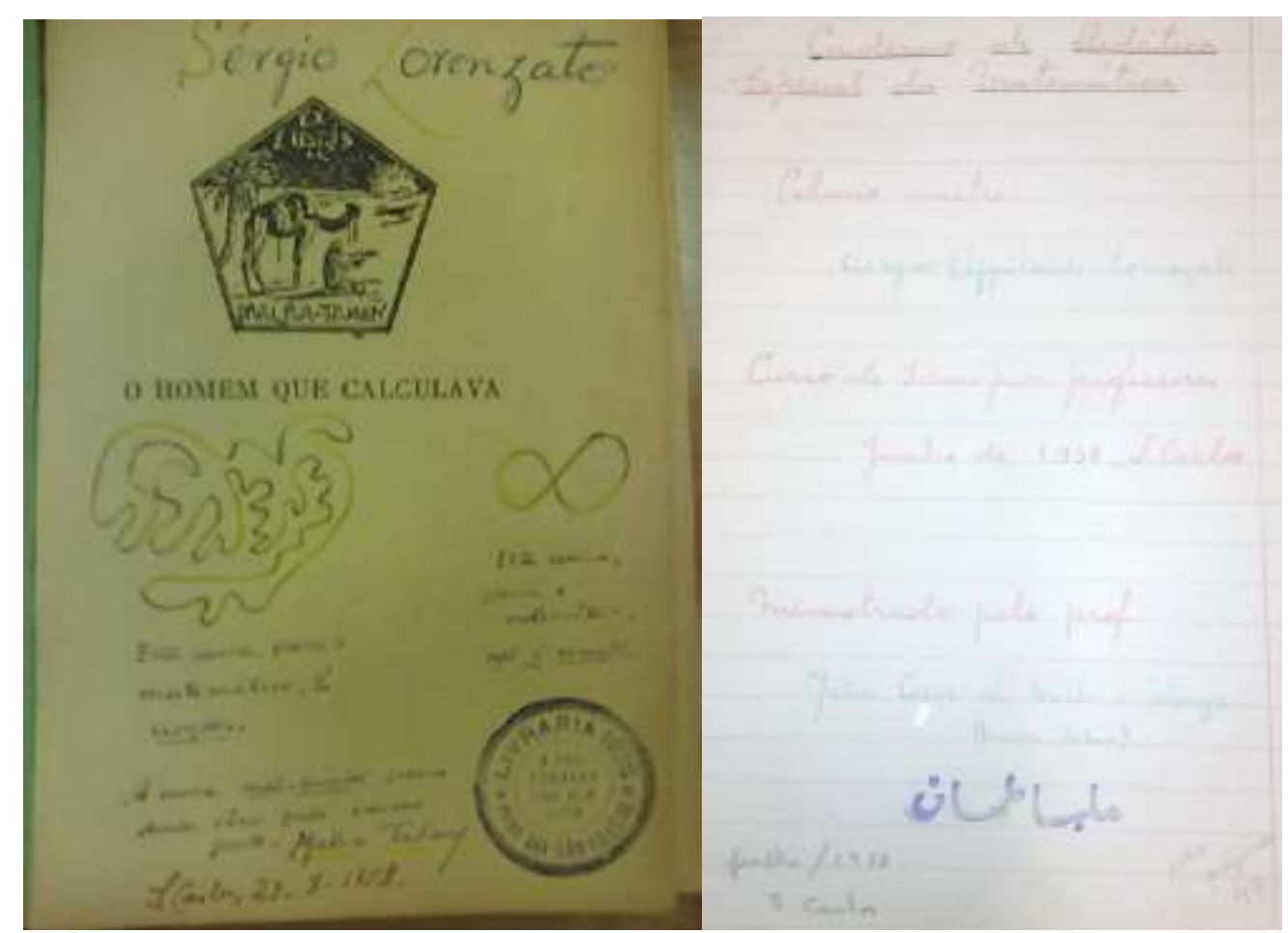

FIGURAS 3 e 4 - Livro e caderno, respectivamente, pertencentes ao professor Lorenzato, e assinados por Malba Tahan

Fonte: [Acervo pessoal do professor Lorenzato]

Por ocasião da Exposição Malbatemática, Lorenzato recebeu das mãos de Renata de Faria Pereira, neta de Malba Tahan, o tinteiro que pertenceu ao seu avô (Figura 5), em reconhecimento da família pelo empenho de Lorenzato em manter viva a memória e o legado de Malba Tahan.

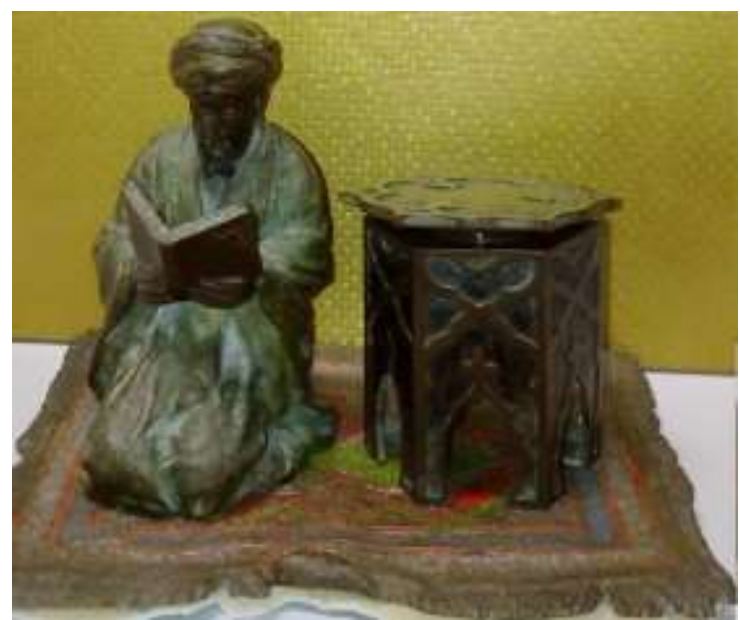

FIGURA 5 - Tinteiro "árabe" usado por Julio Cesar de Mello e Souza Fonte: [Acervo pessoal do professor Lorenzato] 
A "Malbatemática" trouxe à mostra objetos pessoais, fotos, cartas, documentos, manuscritos e publicações de Julio Cesar de Mello e Souza, com o objetivo de divulgar sua vida, sua obra, mas, principalmente, de suscitar a reflexão sobre seu legado e sobre sua contribuição para a Educação Matemática. Essa contribuição já era percebida durante sua atuação profissional. Julio recebeu, em vida, várias homenagens e honrarias: dentre elas, prêmios da Academia Brasileira de Letras, em 1930 (Figura 6), pela obra Céu de Allah, e em 1940 (Figura 7) e 1972, ambas pelo livro $O$ homem que calculava. Também foi membro da Academia Pernambucana de Letras, ocupando a cadeira de no 8.

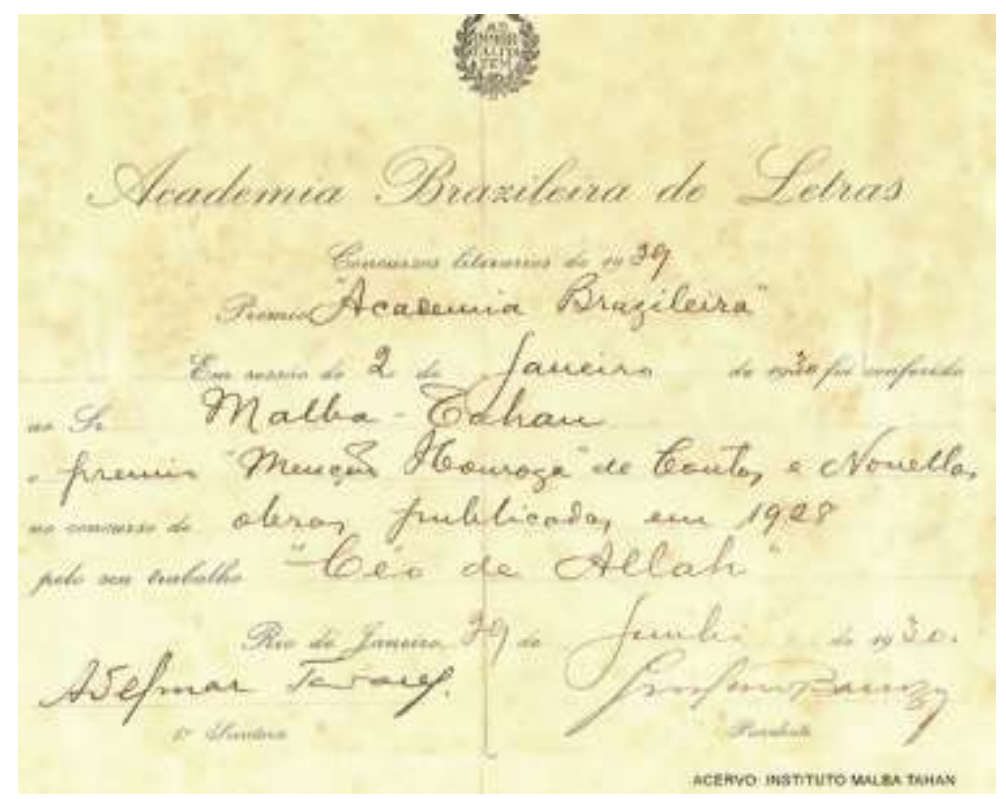

FIGURA 6 - Prêmio da Academia Brasileira de Letras, 1930.

Fonte: [Acervo Malba Tahan do Centro de Memória da Educação da FE/Unicamp]
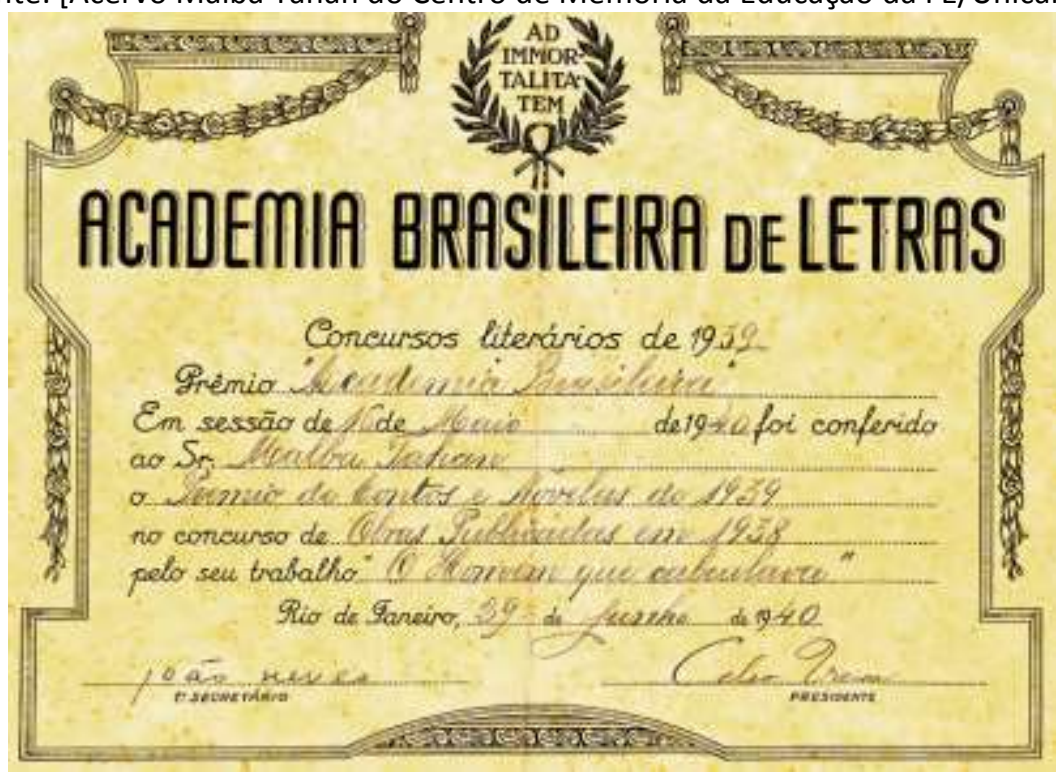

FIGURA 7 - Prêmio da Academia Brasileira de Letras, 1940.

Fonte: [Site oficial de Malba Tahan. Disponível em: http://www.malbatahan.com.br/documentos]

Mas, ainda que seja importante reavivar a memória por meio dos objetos e dos 
documentos, é preciso estabelecer com eles uma relação de historicidade, de valoração e de significação. Essa relação se dá no momento em que emerge, do documento ou do próprio evento, a contribuição que não pode ser esquecida, que não pode se perder no tempo, inclusive pela atualidade que encerra. Esse foi o objetivo maior da exposição e é o objetivo deste texto: ser arauto da matemática que Malba Tahan preconizou em teoria e prática, e pela qual foi e é reconhecido.

Malba Tahan, ao longo do exercício de sua profissão, divulgou a "sua" Matemática por meio de jornais e revistas de diferentes cidades brasileiras. Foi colaborador de 18 jornais: O Imparcial, Diário de São Paulo, O Malho, Gazeta Comercial, Jornal do Comércio, $O$ Povo, Diário de Notícias, Tribuna Popular, O Democrata, Diário da Matta, A República, A Notícia , Última Hora, Folha de S. Paulo, A Noite, Jornal do Brasil, O Correio da Manhã e Diário da Noite.

Além dos jornais, foi colaborador também das revistas: O Cruzeiro, O Tico-Tico, Vida Infantil, Fon-Fon e Vamos ler? Foi ainda editor das revistas Damião, voltada à causa dos doentes de hanseníase, Al-Karismi e Lilaváti, estas dedicadas à matemática. (Figuras 8, 9 e 10).
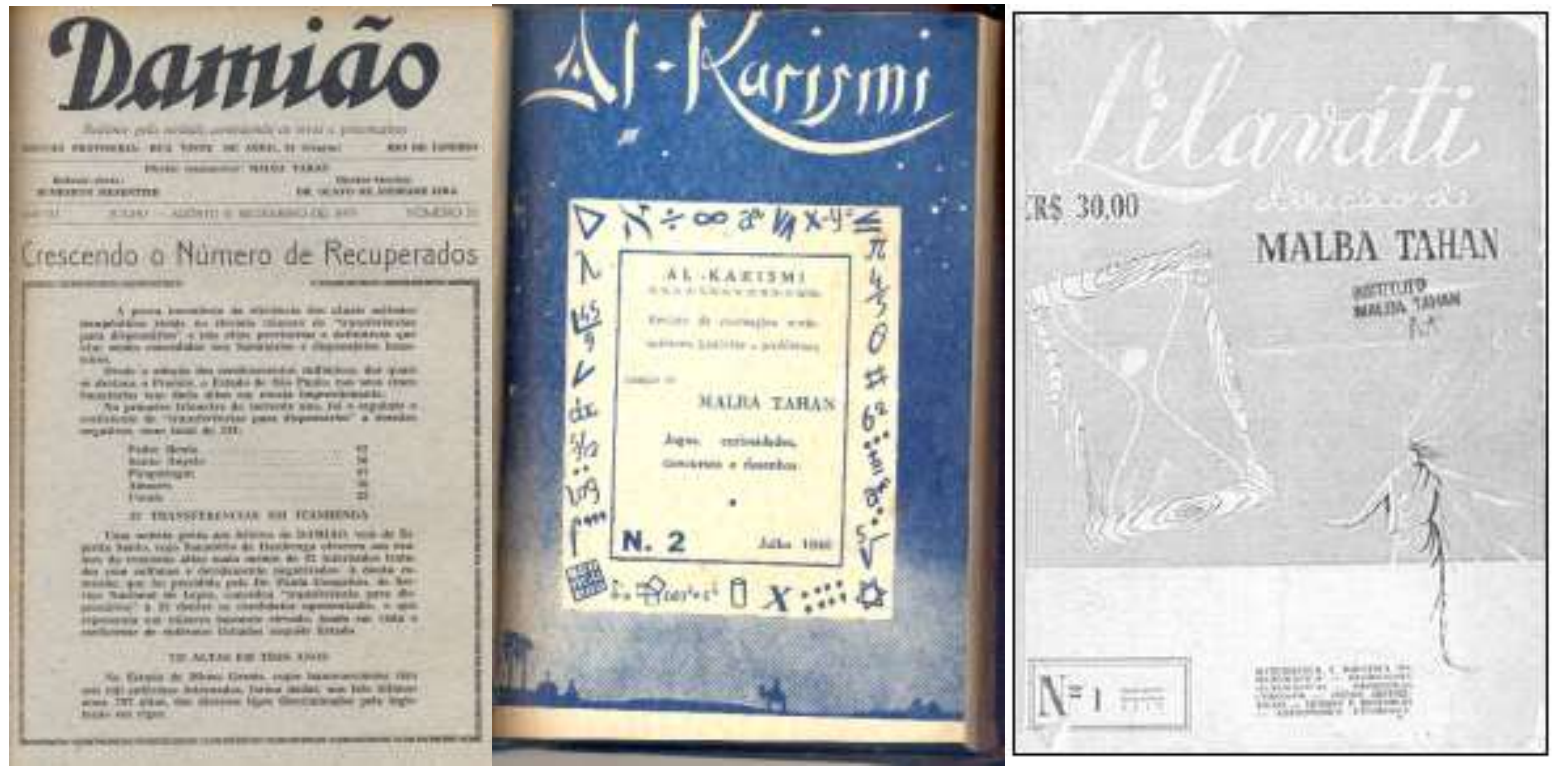

FIGURAS 8, 9 e 10 - Capas das Revistas Damião (1955, n. 21), Al-Karismi $(1946$, no 2) e Lilaváti $(1957$, n. 1)

Fonte: [Acervo Malba Tahan do Centro de Memória da Educação da FE/Unicamp e Filho, 2008, p. 58] 
Malba Tahan foi chamado de "El Indiana Jones de las matemáticas" em reportagem da Revista Newsweek (2012). A mesma reportagem cita que Malba Tahan (Brasil), Martin Gardner (EUA), Samuel Loyd (EUA) e Yakov Perelman (Rússia) são os quatro maiores divulgadores da Matemática da história.

Para Pereira Neto e Salles (2012, p. 69), “... o sonho de Malba Tahan de promover a humanização do ensino da Matemática ainda não foi realizado". Por isso é importante dar continuidade à divulgação de suas ideias.

\section{DO MENINO AO PROFESSOR}

Se estivesse vivo, em 2015 Julio Cesar teria completado 120 anos. Seriam 120 anos de história de uma vida que começou a ser escrita em 6 de maio de 1895, na cidade do Rio de Janeiro, então capital do Brasil, quando veio ao mundo o menino Julinho.

O nome Julio Cesar, nome de imperador, Ihe foi dado pelo pai, que o queria militar. Porém Mello e Souza foi professor como a mãe. Sua história - do menino ao professor Julio escreveria com o tinteiro da singularidade, da originalidade, da determinação, da genialidade. Uma história que se construiu e consolidou ao longo dos 79 anos em que viveu. Julio Cesar faleceu, trabalhando, em 18 de junho de 1974. E sua história, hoje, se intersecciona à própria história da educação matemática no Brasil.

Ainda muito pequeno Julinho mudou-se do Rio de Janeiro para Queluz, onde viveu até os 10 anos de idade - uma vida de menino comum, numa família de nove filhos, dos quais ele era o do meio.

O menino de Queluz morava às margens do Paraíba do Sul, o que Ihe permitia nadar, pescar e ter em seu quintal uma coleção de sapos. Sapos! Isso mesmo! Chegaram a ser cerca de 50 os sapos de estimação. Todos devidamente nomeados. Um deles, o Monsenhor, o acompanhava em seus passeios pela região. Mais tarde, nos cursos que oferecia, os professores, por saberem de seu gosto infantil por sapos, o presenteavam com réplicas de sapos de louça, de ferro, de madeira, de porcelana, etc. Assim, mesmo depois de adulto, continuou a colecionar sapos (Figura 11). 


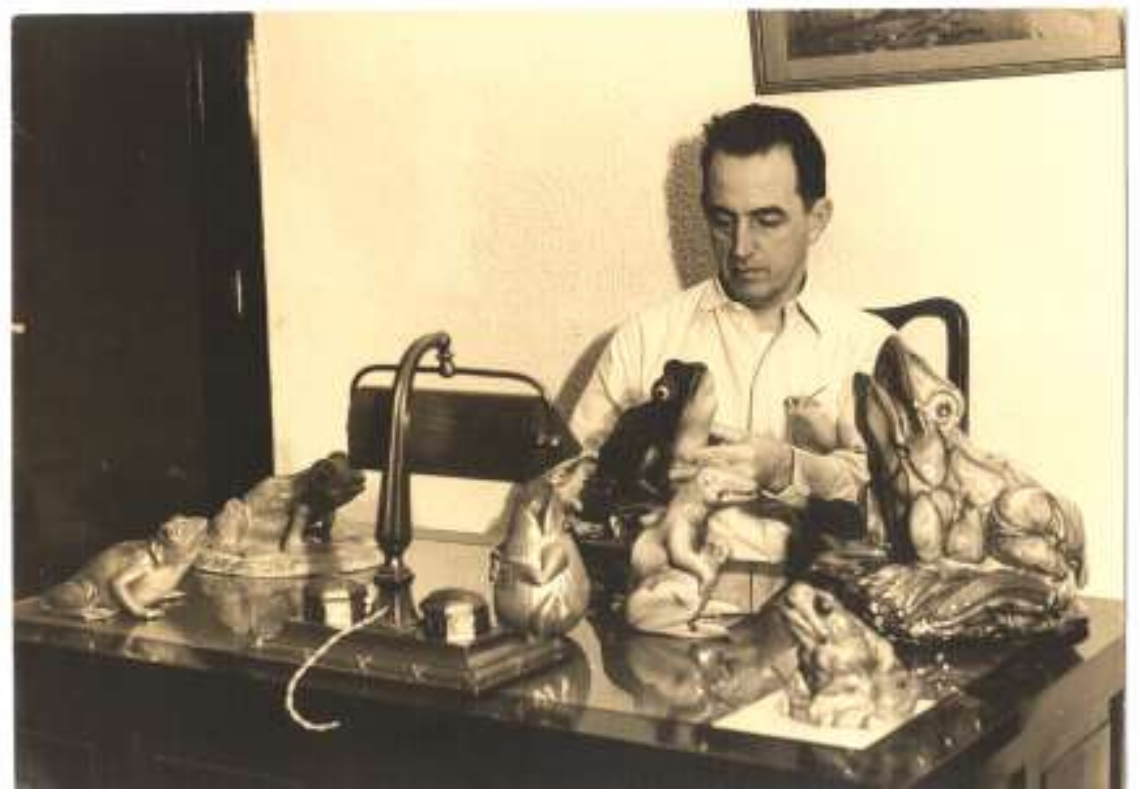

FIGURA 11 - Foto com sua coleção de sapos

Fonte: [Acervo Malba Tahan do Centro de Memória da FE/Unicamp]

Suas origens familiares foram humildes. Seu pai, João de Deus de Mello e Souza (08/03/1863 - 09/03/1911), e sua mãe, Carolina Carlos de Toledo (04/11/1866 01/06/1925), a Dona Sinhá como era conhecida, eram professores em Queluz. Dona Sinhá dava aulas em sua própria casa e Julio Cesar atuava como seu auxiliar: apagava a lousa, distribuía e recolhia cadernos, contava histórias. E assim, talvez sem que se desse conta, já se moldava no menino o futuro professor.

Julinho iniciou o curso primário com sua mãe, mas, em 1906, aos 11 anos, voltou para o Rio de Janeiro e concluiu o curso primário no Colégio Militar. Porém, o pai não podia mais pagar o Colégio Militar e, por essa razão, Julinho passou a estudar no Colégio Pedro II, onde conseguiu uma bolsa de semigratuidade. Esse colégio, à época, era e seria por bom tempo a referência nacional em termos de programas educacionais.

Foi quando estudava nesse colégio que ele fez sua primeira publicação. Tratava-se de um jornal, manuscrito, de uma folha apenas, com tiragem mensal, e limitado a um único exemplar em cada edição: o Erre (Figuras 12 e 13).

Nome misterioso, esquisito, até hoje não explicado, o Erre seria um tempo verbal do verbo errar? Seria o nome da letra R e, portanto, um substantivo? Seja o que for, foram 25 edições ao longo de dois anos (1907-1908). Julio escrevia e distribuía aos colegas, que iam repassando o exemplar de um para outo. Percebe-se nessa sua iniciativa o surgimento do escritor, do editor e do divulgador. 

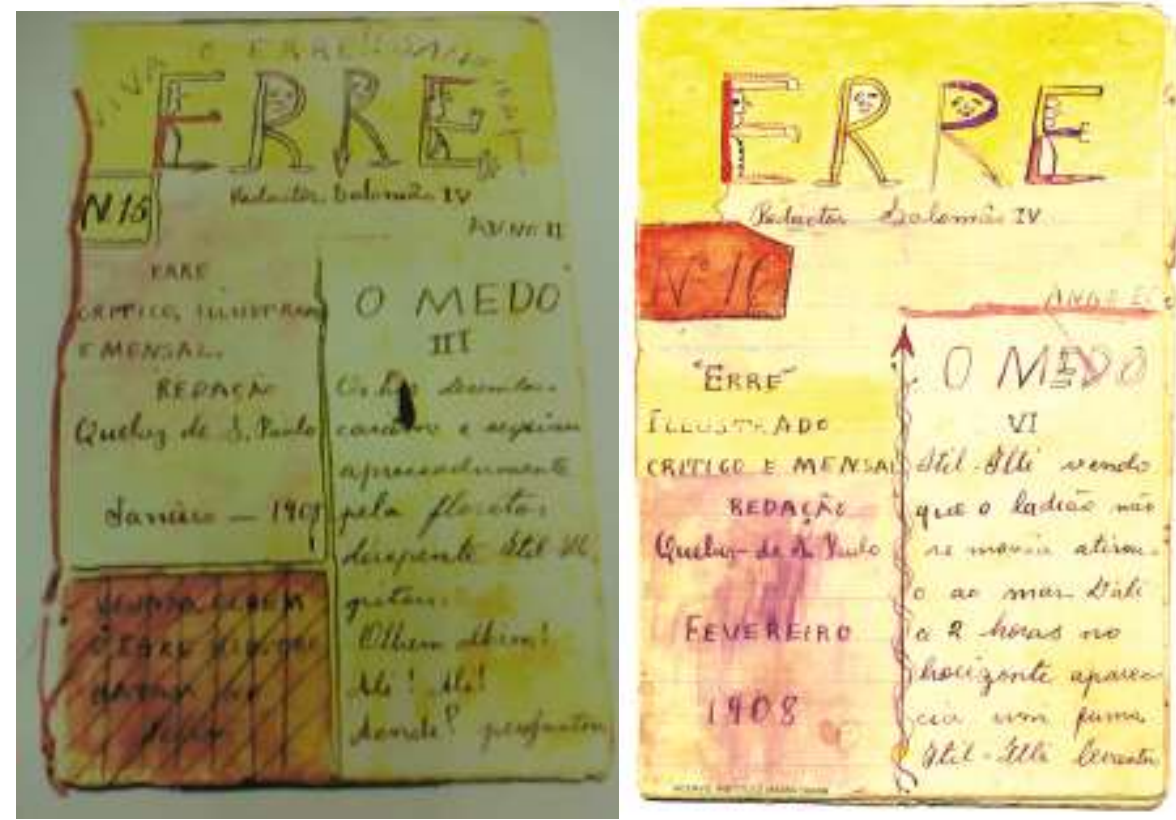

FIGURAS 12 e 13 - Revista Erre, n. 15 e n. 16, respectivamente

Fonte: [Acervo Malba Tahan do Centro de Memória da Educação da FE/UNICAMP]

Julio assinava o Erre com o pseudônimo de Salomão IV. Esse seria o primeiro de vários outros pseudônimos. Em 1918, quando trabalhava no jornal O Imparcial, escreveu quatro contos e levou ao editor para publicá-los. No entanto, seus contos permaneceram por bom tempo esquecidos sob "o peso de uma pedra". Resolveu, então, reapresentá-los, agora assinados pelo professor norte-americano R. V. Slade e traduzidos por Breno de Alencar Bianco. Feito isso, no dia seguinte seus contos estavam na primeira página. Assim Julio entendeu que usar pseudônimos seria uma boa estratégia. E foi.

Julio Cesar de Mello e Souza (Figura 15) chamou a estratégia do uso de pseudônimos de "mistificação literária". Não se tratava apenas de criar um pseudônimo, mas de fazer parecer uma pessoa que realmente existisse. O pseudônimo "Ali Yezid Ibn-Abul Izz-Eddin Ibn-Salin Hank Malba Tahan" reduziu-se a Malba Tahan. "O pseudônimo fora composto pelas palavras Malba, um pequeno oásis localizado no lêmen (Arábia), e Tahan, o moleiro que prepara o trigo, adotado por sugestão de uma aluna da Escola Normal Maria Zechsuk Tahan" (SIQUEIRA FILHO, 2008, p. 44).

Julio Cesar criou, inclusive, uma biografia para Malba Tahan, o que fez com que o pseudônimo ganhasse vida e realmente parecesse o nome de uma pessoa real (Figura 16). E assim, em 1925, publicou Contos de Malba Tahan, sua primeira obra literária, assinada com o pseudônimo que se tornaria definitivo. 


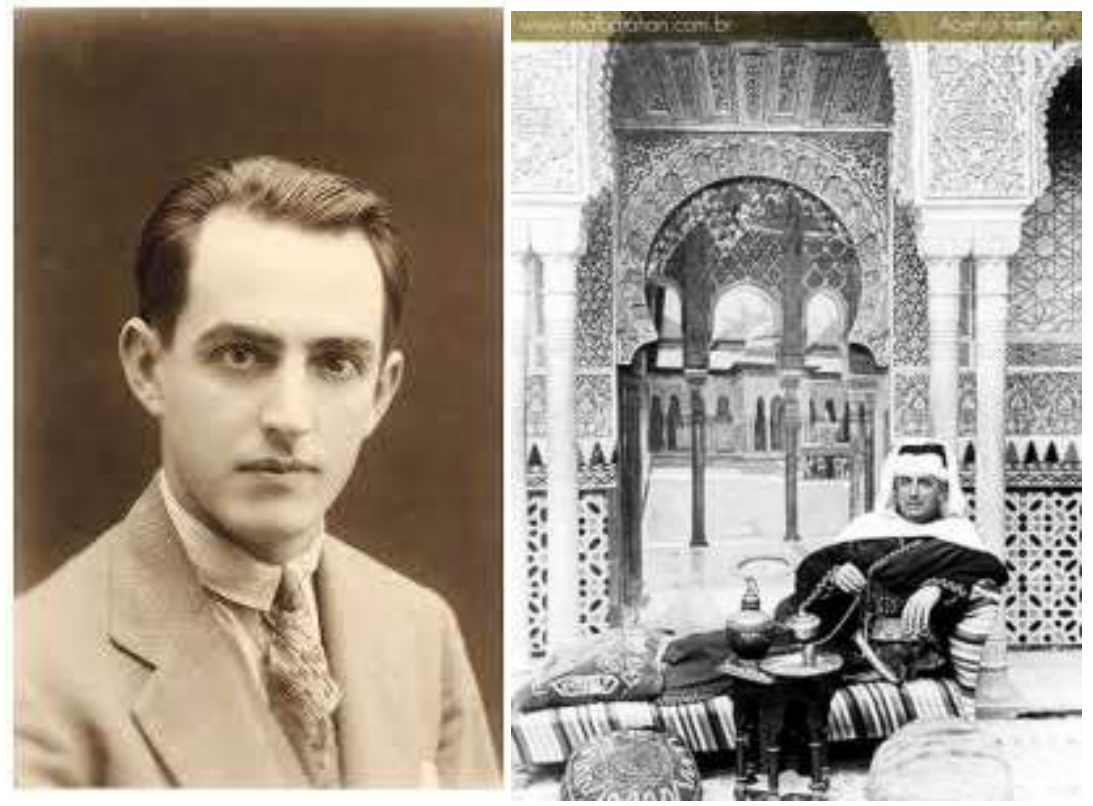

FIGURAS 14 e 15 - Julio Cesar de Mello e Sousa na época em que lançou Contos de Malba Tahan e Malba Tahan a caráter, na década de 1960, respectivamente

Fonte: [Disponível em: https://www.ime.usp.br/caem/anais_mostra_2015/.../Palestra3_Pedro_Salles.pdf]

Seria pelo pseudônimo Malba Tahan que Julio Cesar de Mello e Souza ficaria mundialmente conhecido e famoso. Lorenzato (2015) explica que em 1952, por decreto do então Presidente da República Getúlio Vargas, o pseudônimo foi anexado ao seu nome, passando a constar em sua carteira de identidade (Figura 16).

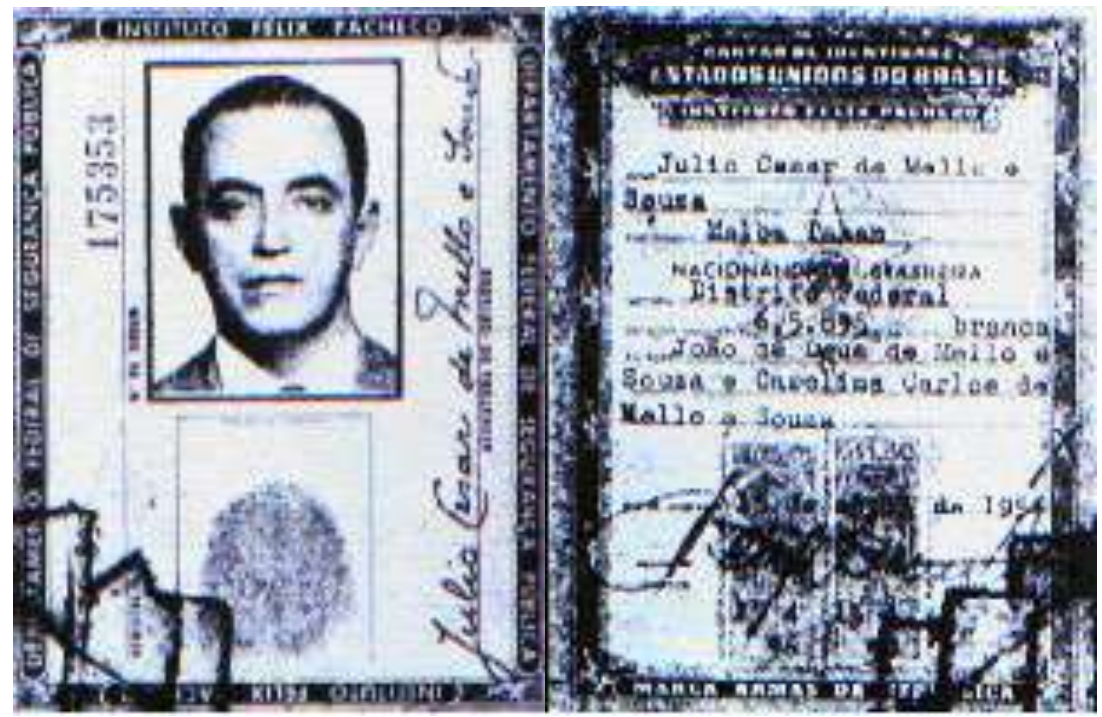

FIGURA 16 - Carteira de identidade de Julio Cesar de Mello e Sousa/Malba Tahan Fonte: [Site Oficial de Malba Tahan. Disponível em: http://www.malbatahan.com.br/documentos] 
Muito provavelmente esse pseudônimo foi escolhido por influência dos seus estudos da cultura árabe. Julio Cesar passou sete anos estudando-a (1918-1925); tornou-se um profundo conhecedor dela e divulgou-a em inúmeras publicações e produções literárias. Um exemplo disso é a Revista Al-Karismi (Figura 9), aqui apresentada por Oliveira (2010, p. 82):

\begin{abstract}
Destinada a alunos e professores de matemática, a publicação trazia em seu discurso a intenção de reflexão, debates e discussões acerca do ensino e da aprendizagem em matemática e de outras tendências que surgiam em meio a esse contexto, sempre valorizando a cultura árabe. [...]. O autor mostra aos leitores que os árabes, em todos os períodos da História, revelaram decidida predileção pelo estudo dessa área.
\end{abstract}

Foi durante o Curso Colegial que Julio Cesar fez a opção pela carreira do magistério. Saindo do Colégio Pedro II, cursou a Escola Normal e obteve o diploma que o habilitava a ser professor primário. De acordo com Siqueira Filho (2008), cursou também a Escola Politécnica, pela qual se formou engenheiro, porém nunca exerceu a profissão. Para ele era mais importante ser professor do que engenheiro, mas o diploma de engenheiro o habilitava a ser professor de matemática.

Começou a lecionar no próprio Colégio Pedro II, depois na Escola Normal. A princípio foi professor de História, Geografia e Física. Mais tarde, optou pela matemática, por meio da qual sua atuação alcançaria maior destaque.

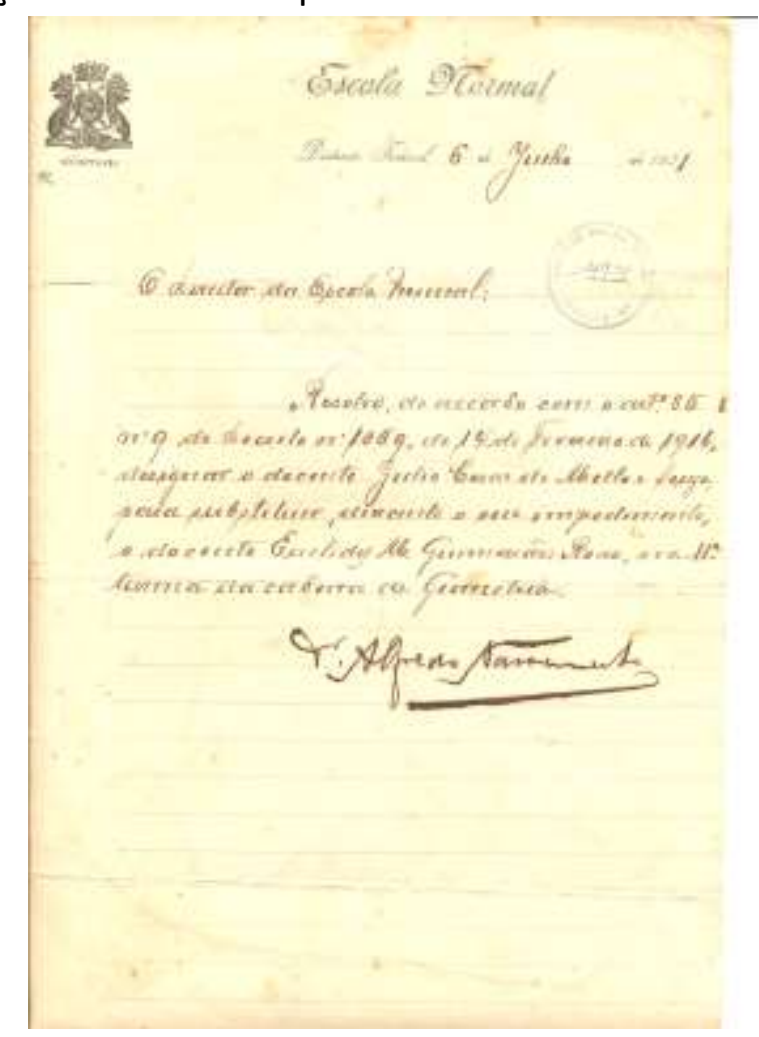

FIGURA 17 - Documento que nomeia Julio Cesar substituto de Euclides Roxo Fonte: [Acervo Malba Tahan do Centro de Memória da Educação FE/Unicamp] 
Em 1921, teve o privilégio de substituir Euclides Roxo, seu ex-professor na Escola Normal (Figura 17). Em 1923, aos 28 anos de idade, tornou-se professor nessa mesma escola, onde lecionaria por 40 anos. Em 1925, aos 30 anos, casou-se com Dona Nair Marques da Costa, uma ex-aluna da Escola Normal, com quem teve três filhos. Em 1937, aos 42 anos, já era professor catedrático da Faculdade de Filosofia Ciências e Letras (FFCL) da Universidade do Brasil, atual Universidade Federal do Rio de Janeiro (UFRJ).

Foi no mesmo ano de 1937 que publicou O homem que calculava. Após essa publicação, entre os anos de 1938 e 1940, Julio Cesar de Mello e Souza teve sua identidade revelada publicamente, o que não the abalou o sucesso e a credibilidade conquistada ao longo dos anos, pela seriedade e consistência do trabalho que realizava no campo da educação e da educação matemática.

Como pagar uma dívida impagável? Como dividir igualmente 8 pães entre 3 pessoas? Como descobrir a cor dos olhos das escravas que mentiam? Como formar um número qualquer, usando quatro quatros? Como se explica o desaparecimento de 1 dinar numa conta de 30 dinares? Esses são apenas alguns dos problemas que compõem os 34 capítulos do seu livro mais famoso, O homem que calculava (1937), campeão de vendas no Brasil e recorde brasileiro de vendas no exterior, traduzido em quinze idiomas (Figura 18).

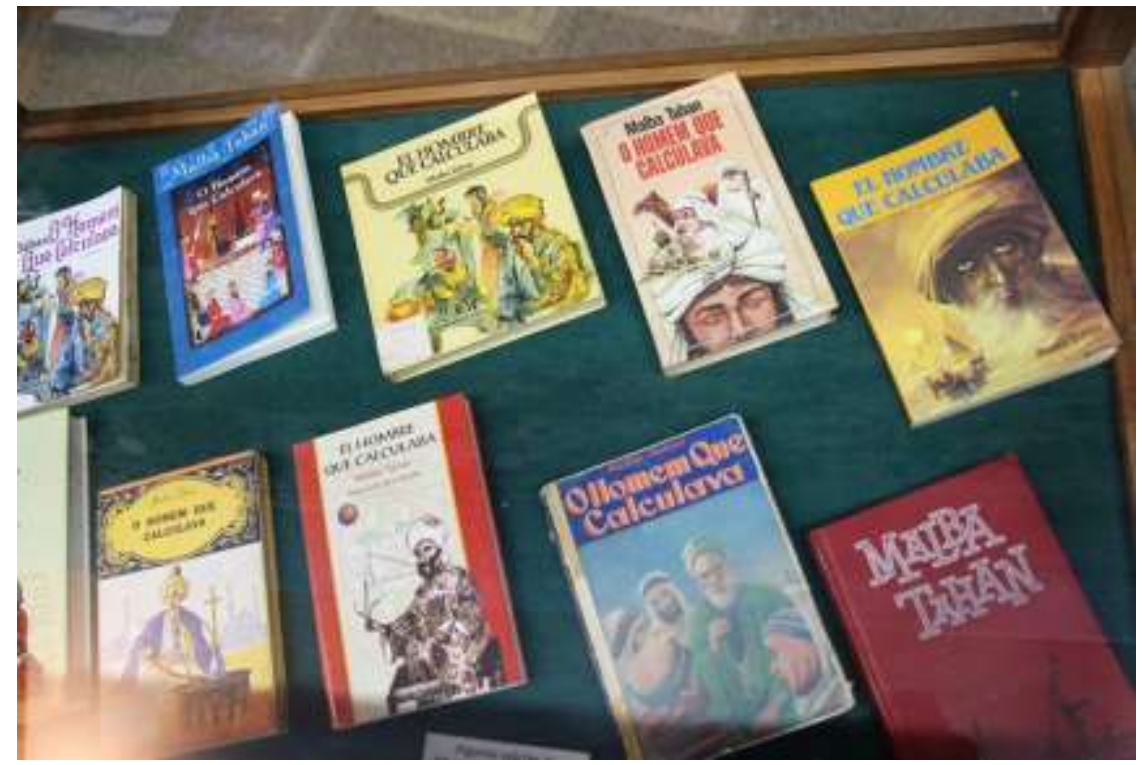

FIGURA 18 - Exemplares de algumas edições do livro O homem que calculava Fontes: [Acervo Malba Tahan do Centro de Memória da Educação da FE/Unicamp e Acervo pessoal do professor Lorenzato]

Um dos problemas mais conhecidos do livro é a partilha dos 35 camelos deixados pelo pai como herança para 3 irmãos. Um deveria receber a metade dos camelos, outro a terça parte e o mais novo, a nona parte. Essa divisão parecia impossível aos herdeiros. 
Afinal, a metade de 35 é 17 e meio (TAHAN, 1998). Assim, seria necessário "fatiar" um camelo, com o que nenhum herdeiro concordou. Mas o homem que calculava resolveu o problema com destreza matemática, mas também com justiça e equidade, sabedoria e ética: a vontade do pai foi respeitada, os filhos receberam a herança a que tinham direito e ainda sobrou um camelo que foi dado ao homem que calculava “... por ter resolvido, a contento de todos, o complicado problema da herança!" (TAHAN, 1998, p. 20). E, com os mesmos princípios com que resolveu o problema dos 35 camelos, são resolvidos outros tantos problemas por Beremiz Samir, o homem que calculava.

Monteiro Lobato, em carta que escreveu a Malba Tahan, datada de 14 de janeiro de 1939 (Figura 19), afirma que 0 homem que calculava é uma obra que "ficará a salvo das vassouradas do tempo", mas que "só necessita de um país que devidamente a admire". Concordamos. A obra é um clássico e, como tal, atemporal.

\section{S.Paulo, $24,2,939$}

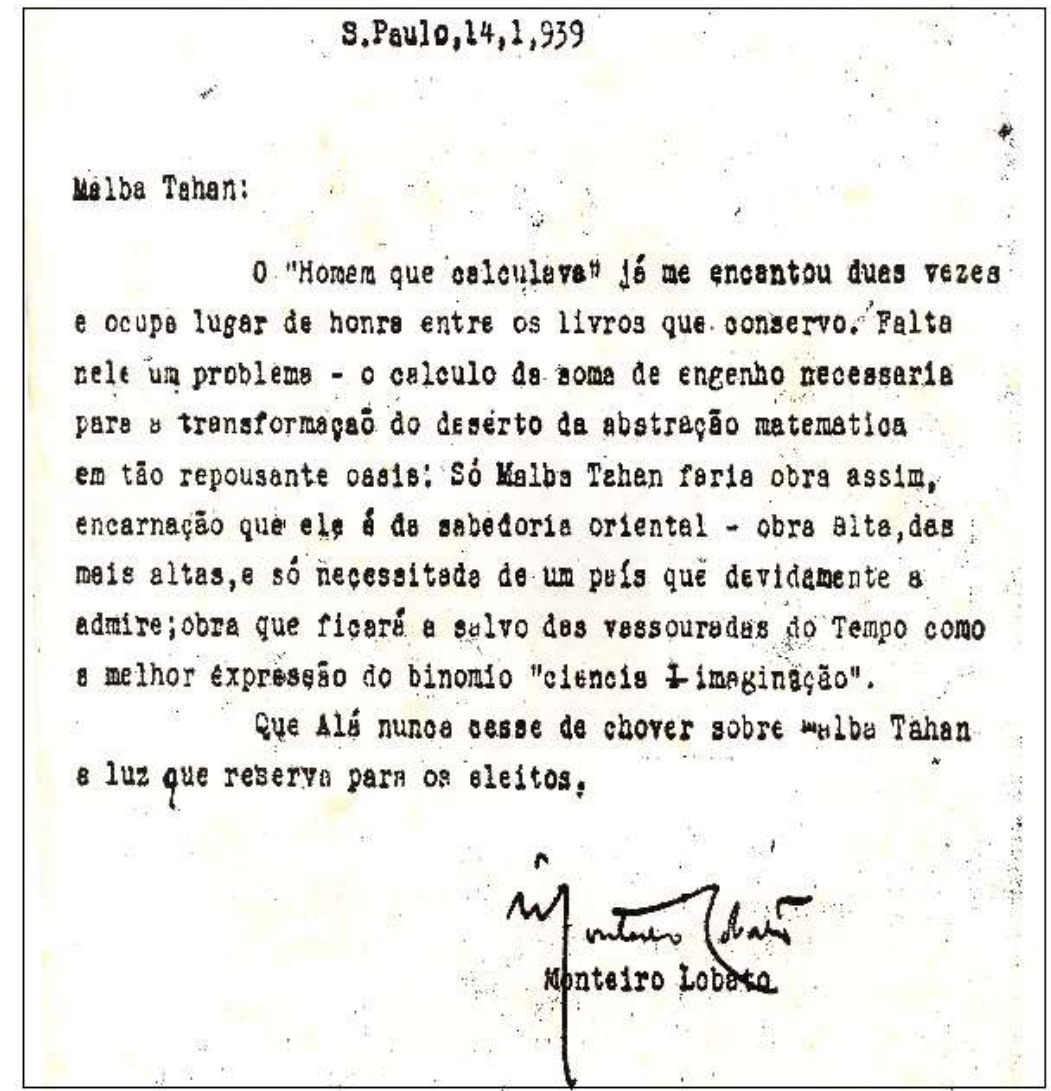

FIGURA 19 - Carta de Monteiro Lobato para Malba Tahan Fonte: [Acervo do Centro de Memória da Educação da FE/Unicamp]

Julio Cesar, no início de sua carreira como professor, fez um curso na Escola Dramática Municipal, no Distrito Federal, Rio de Janeiro, em 1915, certamente não para ser ator, mas para usar a dramaturgia como recurso didático em suas aulas e palestras, na contação de histórias, etc. Ao que parece, Julio não media esforços para ser um bom professor, para encontrar 
estratégias diferentes de ensino e para promover a aprendizagem de seus alunos. Sua prática denotava um professor muito além de seu tempo e revelava também extrema coerência entre o que falava e o que fazia e respeito à ética profissional.

Segundo Oliveira (2010, p. 82), “o professor de Matemática Júlio César de Mello e Souza empenhava-se para cumprir dentro de sua realidade prática em sala de aula ou mesmo em sua postura de ser humano, o que apresentava na fantasia e na literatura".

Vale dizer que, em meio a tudo o que fazia, Julio Cesar encontrava tempo para se dedicar aos doentes de hanseníase. Fazia visitas, mas também dava palestras, que foram cerca de 200, em todos os leprosários que existiam. E tanto tempo dedicava a essa causa que sua esposa chegou a lhe dizer: "Você conhece mais leprosos do que gente sadia".

Aliás, Faria (2011, p. 27) nos mostra que Julio Cesar foi muitos em uma só pessoa:

$$
\begin{aligned}
& \text { O professor de matemática do Colégio Pedro II? O professor do Instituto de } \\
& \text { Educação do Rio de Janeiro? O professor da Universidade do Brasil? O escritor } \\
& \text { Malba Tahan? O defensor da causa dos hansenianos? O contador de histórias? O } \\
& \text { autor de livros didáticos? O autor de livros infantis? O editor das Revistas Al- } \\
& \text { Karismi, Lilaváti e Damião? O jornalista? O arquivista? [...] }
\end{aligned}
$$

De menino a professor de Matemática, provavelmente Julio Cesar, no desenrolar de suas diversas atividades, no decorrer de sua vida e de sua carreira profissional, não se dava conta do quanto suas concepções, suas práticas, suas obras seriam importantes para a história da Educação Matemática. Mas, intuitivamente ou não, sabia que deveria registrar o que fazia, o que pensava. E assim o fez. E que bom que o fez! 


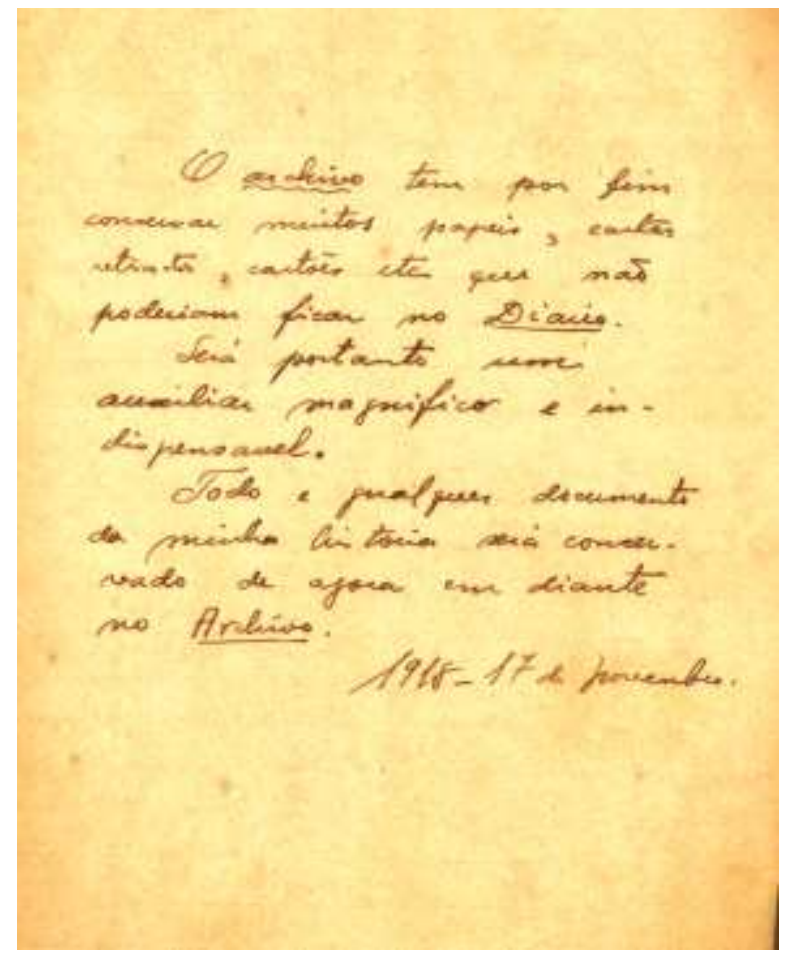

FIGURA 20 - Foto da primeira página do "Archivo"

Fonte: [Acervo Malba Tahan do Centro de Memória da Educação da FE/Unicamp]

Ainda de acordo com Faria (2011), foi em 1918 que Julio Cesar de Mello e Souza iniciou o seu "Archivo" (Figura 20) e o seu Diário.

\begin{abstract}
Naquele momento, o jovem professor-escritor hipotecou documentos para o futuro, apostou em sua história, arquivou correspondências, fotos, postais, recortes de jornais e anotações pessoais. O "Archivo" e o Diário de Júlio César de Mello e Souza revelam um percurso de vida fora dos moldes convencionais, o desejo de fixar a memória individual e profissional e, assim, ter garantias contra o esquecimento (FARIA, 2011, p. 34).
\end{abstract}

E foi graças à decisão de registrar e arquivar suas atividades que Julio Cesar criou seu acervo, o qual, após sua morte, foi doado à Prefeitura Municipal de Queluz. Esta, por sua vez, criou o Museu Malba Tahan, que recebeu muitos visitantes, pesquisadores, promoveu cursos, gincanas, etc.

Porém, em 2007, o professor Sergio Lorenzato (FE/UNICAMP) e a profa Juraci Conceição de Faria, doutoranda da mesma faculdade, propuseram ao prof. Jorge Megid Neto, então diretor da FE, que esforços fossem realizados a fim de conseguir trazer o acervo para o Centro de Memória da Educação (CME) da FE/UNICAMP. Com o apoio do então reitor, José Tadeu Jorge, foram feitas negociações nesse sentido com a Prefeitura de Queluz e com a família, esta representada pela neta Renata de Faria Pereira. Após terem sido tomadas as providências técnicas e legais, o acervo de Malba Tahan foi doado ao CME/FE/UNICAMP, que o recebeu em 6 de maio de 2010 (LORENZATO; FARIA, 2011). 

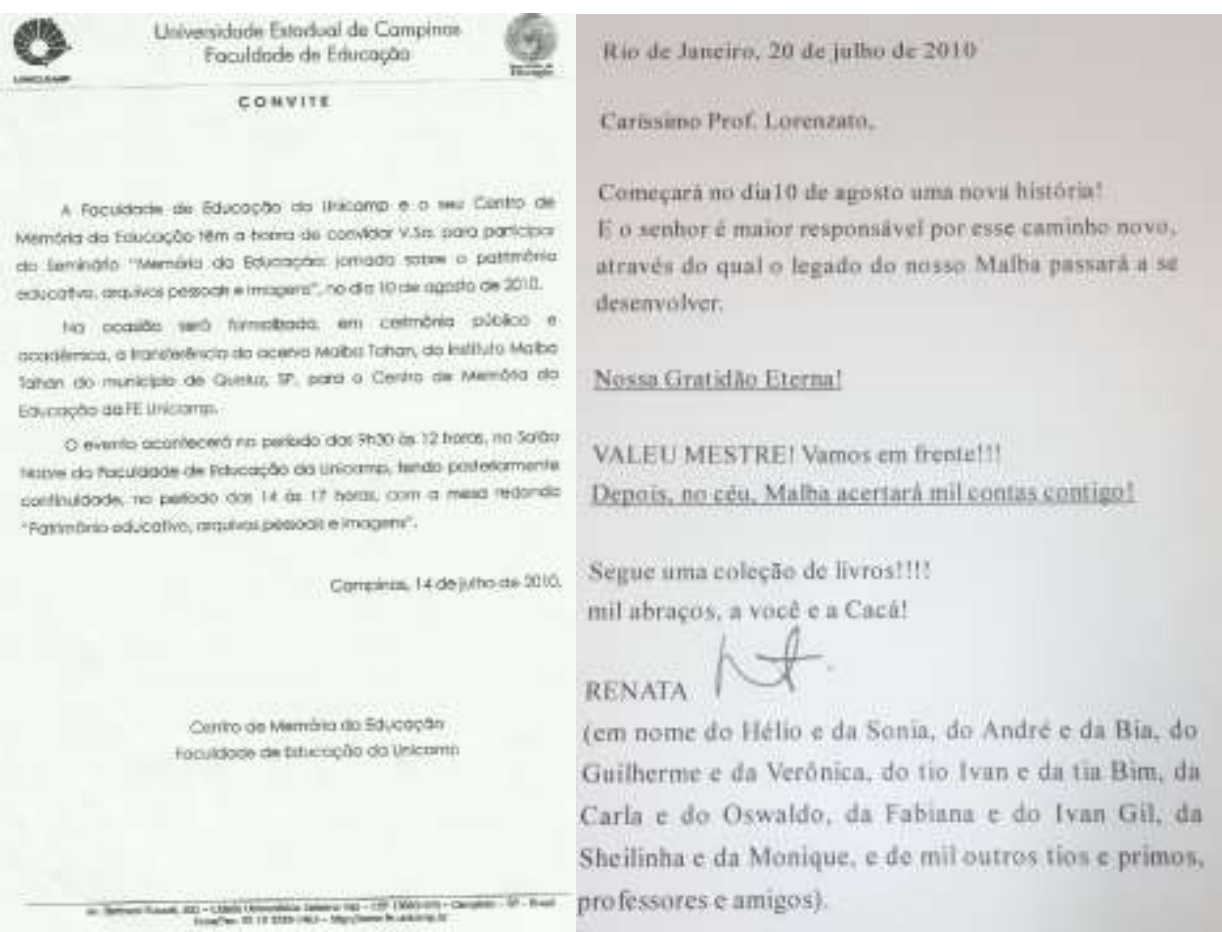

FIGURAS 21 e 22 - Convite para o Seminário realizado em 10 de agosto de 2010 e Carta da neta de Malba Tahan ao professor Sergio Lorenzato, respectivamente.

Fonte: [Arquivo pessoal dos autores]

Em 10 de agosto de 2010, a Faculdade de Educação organizou o Seminário “Memória da Educação: jornada sobre o patrimônio educativo, arquivos pessoais e imagens" (Figuras 21 e 22), durante o qual ocorreu a formalização da transferência do acervo de Malba Tahan, do Instituto Malba Tahan (no município de Queluz/SP), para o Centro de Memória da Educação da FE/Unicamp, estando desde então sob sua custódia.

O coordenador do CME/FE, professor André Luiz Paulilo, estima que o acervo de Malba Tahan tenha entre 15 e 20 mil documentos. Dentre eles, além dos objetos pessoais, constam: cadernos de arquivo, de recortes de jornais, de viagens, de conferências, de aulas; livros; convites; fotos; discursos; telegramas e cartas; artigos; publicações em jornais e revistas; documentos pessoais; manuscritos diversos. Esses documentos vêm sendo analisados, classificados e catalogados para que possam ser utilizados para consulta e pesquisa, e para promover a Matemática da qual Julio Cesar de Mello e Souza foi precursor, protagonista e divulgador incansável. 


\section{UMA JUSTA HOMENAGEM}

Abordamos, neste texto, fatos, momentos, práticas, etc., vivenciados por Julio Cesar de Mello e Souza-Malba Tahan.

Tivemos, como pano de fundo, a exposição "Malbatemática", que trouxe à mostra parte do acervo de Malba Tahan, com o objetivo de prestar homenagem à sua vida e à sua obra. Durante a exposição ocorreu também a palestra "Vida e obra de Malba Tahan", proferida pelo professor Sergio Lorenzato.

Mostra e palestra dialogaram no sentido de não somente reverenciar a memória ou recordar feitos, mas, principalmente, estabelecer a relação histórica entre o passado e o presente, no que tange à contribuição de Malba Tahan para a educação matemática, a formação de professores, a qualidade do ensino e da aprendizagem dos alunos - para a educação em geral.

Resgatamos algumas de suas várias facetas que, como vimos, são muitas. Procuramos enfatizar os princípios e as concepções que fundamentavam a sua prática e chamar a atenção para o grande valor de sua contribuição para a Educação Matemática brasileira. Contribuição que permanece atual, apesar do tempo e da evolução dessa área de estudos no Brasil.

Concordamos que Julio Cesar de Mello e Souza-Malba Tahan mereceu a justa homenagem que recebeu com a institucionalização do Dia Nacional da Matemática. $O$ evento "Malbatemática" foi uma forma de concretizar essa homenagem. O evento passou, porém o que não pode passar é o que aprendemos de Malba Tahan: a matemática que preconizou e protagonizou, em teoria e prática, pela qual é reconhecido; a postura profissional; as concepções de matemática e de ensino-aprendizagem de matemática; a metodologia; a preocupação com a formação; o compromisso ético com a profissão; etc., etc.

Que as lições do mestre possam nos inspirar a sermos também arautos da matemática que ele mostrou ser possível de ensinar e aprender! 


\section{REFERÊNCIAS}

BRASIL. Lei 12 835/2013. Institui o Dia Nacional da Matemática. Diário Oficial da União (D.O.U.), Brasília, 27 jun. 2013. Col. 03, p. 01 - Disponível em:

http://www.jusbrasil.com.br/diarios/56016228/dou-secao-1-27-06-2013-pg-1 Acesso em 06 set. 2016

CICCO. El Indiana Jones de las matemáticas. Revista Newsweek, Argentina, p. 58-60, nov. 2012.

FARIA, J. C. de. Diários de viagem de Malba Tahan: história e memória da formação de professores de matemática da CADES. Tese (Doutorado em Educação) - Faculdade de Educação, Unicamp, Campinas, 2011.

LORENZATO, S. 6 de maio, Dia Nacional da Matemática. Revista de História da Educação Matemática - HISTEMAT- Sociedade Brasileira de História da Matemática - SBHMat, São Paulo, ano 1, n. 1, p. 4-12, 2015.

LORENZATO, S. Para aprender matemática. 3. ed. Campinas, SP: Autores Associados, 2010.

LORENZATO, S. um (re)encontro com Malba Tahan. Zetetiké - FE/CEMPEM/ UNICAMP, Campinas, SP, ano 3, n. 4, p. 95-102, 1995.

LORENZATO, S.; FARIA, J. C. de. Um pouco da história do acervo Malba Tahan: o testemunho de um predestinado. Ciências em Foco, Campinas, SP, v. 1, n. 4, 2011. Disponível em: http://ojs.fe.unicamp.br/ged/cef/article/view/4566. Acesso em: 25 jun. 2016.

LIVEIRA, Cristiane C. Do menino "Julinho" à Malba Tahan: uma viagem pelo oásis do ensino da matemática. Dissertação (Mestrado em Educação) - Instituto de Geociências e Ciências Exatas, Universidade Estadual Paulista, Rio Claro, 2001.

OLIVEIRA, Cristiane C. O homem que lecionava. Revista de História da Biblioteca Nacional, Rio de Janeiro, Especial n. 2, p. 80-83, nov. 2010.

PEREIRA NETO, André de F.; SALLES, P. P. O homem que criava. Revista de História da Biblioteca Nacional, Rio de Janeiro, ano 7, n. 8, p. 66-69, set. 2012.

SIQUEIRA FILHO, M. G. Ali lezid Izz-Edim Ibn Salim Hank Malba Tahan: episódios do nascimento e manutenção de um autor - personagem. Tese (Doutorado em Educação) FE/UNICAMP, Campinas, 2008. Disponível em <http://www.bibliotecadigital.unicamp.br> Acesso em: 25 jun.2016.

SITE OFICIAL DE MALBA TAHAN. Disponível em: www.malbatahan.com.br. 
SUGIMOTO, L. O ensinar e aprender matemática e o tributo ao 'homem que calculava'. Jornal da Unicamp, 06 jul. 2015. Disponível em: http://www.unicamp.br/unicamp/noticias/2015/07/06/o-ensinar-e-aprender-matematicae-o-tributo-ao-homem-que-calculava. Acesso em: 06 set. 2016.

TAHAN, M. O homem que calculava. 47. ed. Rio de Janeiro: Record, 1998.

TAHAN, M. Didática da Matemática. 2. ed. São Paulo: Saraiva, 1965. 2v.

\section{Agradecimentos}

Nossos agradecimentos, primeiramente, a todos que, de alguma forma, se mobilizaram no decorrer do processo de transferência do acervo de Malba Tahan para o Centro de Memória da Educação da FE/UNICAMP. Aos membros do Grupo de Estudos e Pesquisa em Educação Matemática nos/dos Anos Iniciais (GEPEMAI), que não pouparam esforços para que a exposição se realizasse. Aos organizadores do $\mathrm{V}$ Seminário Nacional de Histórias e Investigações de/em Aulas de Matemática (SHIAM), por cederem o espaço e, assim, tornar possível a Exposição Malbatemática. Aos familiares de Malba Tahan, que prestigiaram a exposição com sua presença. A todas as pessoas que contribuíram com seu trabalho para que a exposição acontecesse.

\footnotetext{
' Estamos usando a escrita do seu nome tal qual se encontra em sua Carteira de identidade.

ii Visite o site do GEPEMAI: http://gepemaiunicamp.wix.com/educacaomatematica.
} 